\title{
Una hacienda en jaque: el Mayorazgo de Huasán y los desafíos de las transformaciones del siglo XIX (Argentina)
}

\author{
An hacienda in check: The Huasán Mayorazgo and the challenges of the 19th century transformations (Argentina)
}

Roxana Boixadós

Universidad de Buenos Aires/Universidad Nacional de

Quilmes/Consejo Nacional de Investigaciones Cientificas y

Técnicas, Argentina

roxboixados@gmail.com

Lorena B. Rodriguez

Universidad de Buenos Aires /Consejo Nacional de

Investigaciones Cientificas y Técnicas, Argentina

rodriguezlo@hotmail.com
DOI: https://doi.org/10.24215/15155994e139

Redalyc: http://www.redalyc.org/articulo.oa?id=84563515001

Recepción: 12 Mayo 2019

Aprobación: 16 Marzo 2020

\section{Resumen:}

El mayorazgo de Huasán, fundado a mediados del siglo XVIII en la gobernación del Tucumán (actual territorio argentino), comprendió extensos dominios y se perfiló como un próspero complejo agropecuario, con proyecciones en el comercio y la minería. En el siglo XIX enfrentó los desafíos de las coyunturas políticas provinciales y nacionales, además de diversas transformaciones económicas y sociales hasta su definitiva desvinculación, en 1869. Este artículo presenta los avances de una investigación en curso sobre la formación y funcionamiento del mayorazgo de Huasán considerándolo como un emprendimiento económico, flexible y diversificado, antes que una institución rígida orientada a sustentar exclusivamente una memoria genealógica familiar. Sostenemos que si bien el carácter dinámico -característico de la formación del mayorazgo- fue difícil de sostener en el largo plazo, los largos litigios sucesorios y la intensa conflictividad intrafamiliar resultaron críticos para la gestión de la empresa y el patrimonio.

Palabras Clave: Mayorazgo, Empresa agrícola y ganadera, Conflictos sucesorios, Catamarca, Siglos XVIII y XIX, Historia agraria.

\section{AbStract:}

The mayorazgo of Huasán, founded in the mid-eighteenth century in the governorate of Tucumán (current Argentine territory), included extensive domains and was outlined as a prosperous agricultural complex, with projections in trade and mining. In the nineteenth century it faced the challenges of provincial and national political conjunctures, as well as various economic and social transformations until his definitive disengagement, in 1869. This article presents the advances of an ongoing research on the formation and functioning of Huasán's mayorazgo considering it as an economic enterprise, flexible and diversified, rather than a rigid institution oriented to exclusively sustain a family genealogical memory. We maintain that although the dynamic nature characteristic of the formation of the mayorazgo- was difficult to sustain in the long term, long inheritance litigation and intense intra-family conflict were critical for the management of the company and the heritage.

KEYWORDS: Mayorazgo, Agrarian history, Agricultural and livestock company, Inheritance conflicts, Catamarca, 18th \& 19th centuries.

\section{INTRODUCCIÓN}

El mayorazgo de Huasán, fundado a mediados del siglo XVIII en la antigua gobernación del Tucumán (virreinato del Perú), comprendió extensos dominios sobre tierras dispersas ubicadas tanto en la jurisdicción de Catamarca como en la de Tucumán. Creado por vía testamentaria por el español don Luis Josep Díaz, Huasán se perfiló en tiempos coloniales como un complejo que comprendía la hacienda principal, estancias 
para la cría de ganado, además de minas cuya explotación era incipiente. El centro estaba en Huasán, hacienda situada en el valle de Andalgalá -rodeado por el cerro Ambato, el Nevado de Aconquija y el cerro Atajoque al cobijar varios ambientes en su interior configuraba un espacio ideal para las actividades agropecuarias. Otros valles cercanos, tierras con potencialidad para la explotación minera e, incluso, zonas altas óptimas para pasturas, articulaban sus recursos con la producción de la hacienda integrando así un complejo de carácter diversificado que lo caracterizaría a lo largo del tiempo.

Mapa 1: Ubicación aproximada de las propiedades del Mayorazgo vinculadas

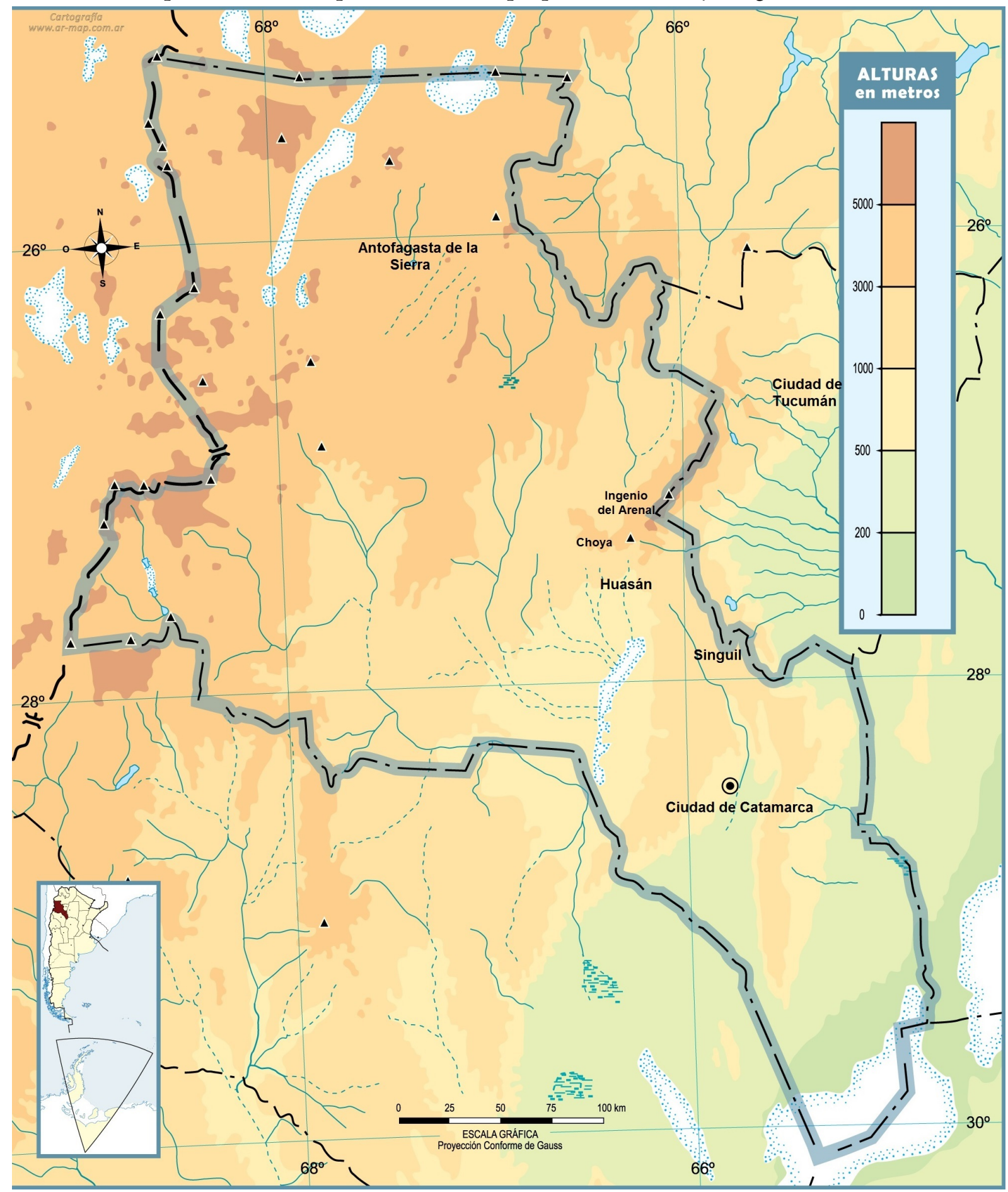

Fuente: Elaboración propia a partir del "Mapa Físico de la Provincia de Catamarca”. Disponible en http://mapoteca.educ.ar/.files/index.html.1.7.html 
Ahora bien, como unidad productiva, el mayorazgo enfrentó en el siglo XIX dos grandes desafíos: por un lado, las guerras civiles que afectaron a la Confederación Argentina en las décadas posteriores a la independencia y que obligaron a su titular a exiliarse durante varios años, mientras se implementaban lentas pero significativas transformaciones económicas y sociales en el contexto de formación de los estados provincial y nacional, en el que el mayorazgo representaba un resabio colonial. Por otro lado, dos grandes conflictos sucesorios a los que se le sumaron distintas demandas por su administración. Con todo, el mayorazgo se mantuvo vigente hasta 1869 , momento en el que su último titular solicitó la desvinculación del patrimonio por vía judicial.

Un conjunto nutrido y diverso de fuentes atesoradas principalmente en el Archivo Histórico de la Provincia de Catamarca (en adelante AHC) da cuenta del complejo funcionamiento productivo del mayorazgo, de los beneficios obtenidos del arrendamiento de tierras, del alquiler de bienes (el molino), pero igualmente de los problemas relacionados con el abasto de agua tanto como de las inmensas extensiones que permanecían improductivas. También se conservaron testamentos y largos expedientes referidos a los litigios por la sucesión y la administración de los bienes del mayorazgo, resultados de las desavenencias y los conflictos de intereses entre los miembros de la familia. La historia de los descendientes del fundador, tramados en el desarrollo de estos litigios, resultan centrales para comprender la crisis de la institución y la decisión final de terminar con ella.

Este artículo presenta los avances de un análisis preliminar sobre la formación y funcionamiento del Mayorazgo de Huasán y de su relación con los cambios económicos, políticos e institucionales que transformaron a la sociedad catamarqueña durante el siglo XIX. En el marco de una investigación interdisciplinaria de carácter regional (en el Noroeste argentino) sobre patrimonio y tierras indivisas, 1 el estudio de este mayorazgo presenta algunas particularidades interesantes: en su origen articuló distintas actividades productivas y extractivas combinando prestaciones laborales donde la servidumbre $-\mathrm{y}$ la esclavitud- convivió con formas asalariadas durante largas décadas. Una de las primeras inquietudes que guiaron esta investigación fue comprender de qué manera una institución con una fuerte impronta señorial logró sostener una prolongada continuidad después de la colonia.

En efecto, los mayorazgos tienen su origen en antiguas disposiciones medievales castellanas destinadas a mantener indivisas extensas propiedades rurales para ser usufructuadas por un solo heredero (sucesor) en cada generación; el titular era el encargado de su administración y debía velar por su preservación. Estas creaciones nobiliarias, destinadas a perpetuar la memoria de los ancestros fundadores y de su apellido como marca distintiva de su linajes, estuvieron reguladas por las Leyes de Toro (1505) que estipulaban los derechos de los testadores de utilizar una parte de sus bienes (un tercio más el quinto de libre disposición) para vincular sus propiedades y fundar un mayorazgo (Mariluz Urquijo, 1970; Clavero, 1974; Núñez Moreno, 1984; Beceiro Pita y Córdoba de la Llave, 1990). Una vez instituido, se esperaba que el mayorazgo constituyera la base material perdurable e inalterable de aquello que estaba por naturaleza destinado al cambio permanente: la familia. Es por eso que la imposición de uno o dos apellidos emblemáticos de uso obligatorio para quienes los sucedieran como titulares -o "señores"- era esencial para conjurar el curso del tiempo y los cambios que necesariamente conlleva la vida familiar. Los mayorazgos se proyectaban así como metáforas superadoras de los ciclos vitales y como tales suspendidas en una temporalidad inmóvil (Smietniansky y Boixadós, 2015).

Estas características asocian a los mayorazgos a una base nobiliaria y rentista en la que predominaban formas y relaciones sociales de producción compatibles con regímenes de servidumbre signados por antiguas tradiciones. Sin embargo, la experiencia de la conquista americana mostró que en los contextos de colonización esta antigua institución podía convertirse en una nueva herramienta de dominación social y económica, donde lo señorial se articulaba con otras formas de explotación de la mano de obra. De este modo, los mayorazgos comenzaron a crearse en la temprana colonia en toda Hispanoamérica, advirtiéndose su crecimiento en el siglo XVIII. La temática fue estudiada fundamentalmente en el virreinato de Nueva España (Fernández de Recas, 1968; Ladd, 1986; Artís Espriu, 1994; Cramaussel, 2010; Gómez Serrano, 
2006 y 2017), así como también en el del Perú (Presta, 1999; Doucet, 2006; Rangel, 2013). El clásico trabajo de Gloria Artís Espriu mostró ya en 1994 cómo la elite colonial de la ciudad de México había diversificado sus actividades e inversiones en haciendas y estancias -dedicadas a la agricultura y la ganadería-, en el comercio y en la minería a lo largo de tres siglos, analizando la importancia de los mayorazgos en la conformación de la base económica de este grupo social. Su investigación avanzó al plantear a estas instituciones como parte de estrategias que aseguraban la inviolabilidad de ciertos bienes productivos (como bienes o tierras indivisas) mientras que otros quedaban sujetos a las contingencias de los ciclos económicos locales y al curso de la economía colonial en general. No quedaron fuera de su atenta mirada las tramas de las relaciones sociales y económicas tejidas entre las familias propietarias de mayorazgos y las decisiones que cada generación debió tomar evaluando diferentes emprendimientos para sostener, ampliar o recuperar un patrimonio familiar. La autora buscó comprender la dinámica histórica entre la pertenencia a un status social de elite (u oligarquía) y la construcción de la fortuna, relaciones en las que los mayorazgos jugaron un rol significativo. Recuperamos dos de sus propuestas en nuestro enfoque: por un lado, la conceptualización del mayorazgo como un "recurso eficiente" al que echar mano para preservar parte del patrimonio a través de la indivisión, según sus conveniencias, y por otro, el abordaje de los mayorazgos como piezas integradas en emprendimientos económicos diversificados, adaptables a las oportunidades -o limitaciones- propias de cada contexto histórico.

Con respecto a los mayorazgos de la antigua gobernación del Tucumán perteneciente al virreinato del Perú, se estudiaron de manera dispar siete casos: Tojo en Jujuy y Salta, parte de un señorío más vasto que comprendía haciendas en el sur de Bolivia (Madrazo, 1990; Teruel, 2016), Ambato, Anillaco y Huasán en Catamarca (Bustos Argañaráz, 1979; Guzmán, 1985; Brizuela del Moral, 2003; de la Orden de Peracca, 2016), Tótox en Córdoba (Serrano Redonnet, 1992), y en La Rioja Sañogasta y Cochangasta (Serrano Redonnet, 1992; Boixadós, 1999, 2001; Farberman y Boixadós, 2015). En la mayoría de estos estudios se combina el enfoque genealógico con aproximaciones desde la historia social de la formación de las elites locales y regionales; el estudio pionero de Guillermo Madrazo sobre el mayorazgo del Marquesado del Valle de Tojo enfocó en cambio la dimensión económica y empresarial de este complejo productivo, sustento de la construcción de una perdurable notabilidad familiar que trascendió los límites de la frontera entre Argentina y Bolivia en el siglo XIX. Recientemente Ana Teruel aportó una reconstrucción minuciosa del patrimonio territorial del mayorazgo cuya dinámica productividad agropecuaria respondió a las demandas de las explotaciones mineras de Potosí, Porco, Chicha y Lipez. También aquí la arquitectura empresarial colonial integró recursos productivos de diversos pisos ecológicos, desde los valles templados y las yungas hasta la puna, en estancias, haciendas, viñas, potreros y sitios de extracción de mineral, recurriendo a la mano de obra indígena (encomiendas y yanaconazgo), esclavos y a la percepción de arriendos y tributos (Teruel, 2016).

Los aportes de estos autores nos permiten reconocer el carácter excepcional del mayorazgo de Huasán en el contexto regional; en primer lugar, se trata de un mayorazgo de fundación tardía (1768), no asociado -como todos los de la gobernación del Tucumán- a familias descendientes de guerreros y colonizadores. Huasán no fue instituido para sostener la memoria de quienes protagonizaron la "gesta conquistadora"; a pesar de su expresa mención en el testamento, la prosapia del fundador quedó en segundo plano. Sostenemos, y toda la argumentación de este trabajo apuntará a demostrarlo, que Huasán fue sobre todo un emprendimiento económico complejo, de base agrícola y ganadero con proyecciones en el comercio y la minería. Para abordar el mayorazgo desde esta perspectiva resulta pertinente comenzar por examinar a su fundador, ya que en su perfil social, su entorno familiar y en su experiencia americana vislumbramos las primeras pistas de un proyecto personal diseñado para perdurar. 


\section{EL FUNDADOR Y SU PROYECTO}

La información sobre el fundador, don Luis José Díaz, procede de varios estudios genealógicos que nos asisten en esta aventura de descubrir aspectos de su identidad que su exitosa carrera burocrática y militar en las colonias americanas, la importante acumulación de bienes y caudales, y la creación del mayorazgo habrán de resignificar de manera notable (Vilgré La Madrid, 1977; Bustos Argañaráz, 1979; Guzmán, 1985; Acuña, 2016). Sabemos que nació alrededor de 1707 en el Puerto de Santa María en Cádiz, España, activo centro que ofrecía excelentes oportunidades a quienes participaban del comercio con las Indias. Negocios mercantiles diversificados (ropa, alimentos, insumos de todo tipo) y de diferente calibre se daban cita en una ciudad cosmopolita, que atrajo inmigrantes de distintas partes de España y del extranjero, y que experimentó un período de "prosperidad espectacular" en las décadas de 1770 y 1780 (Fernández Pérez, 1997).

El genealogista Segundo E. Acuña (2016) individualizó al padre de don Luis en un padrón del puerto de Santa María de 1706 donde figuraba simplemente como "navegante", no clasificado como "don". Su madre en cambio ostentaba un apellido de connotado prestigio social, aunque todavía su ascendencia permanece en sombras. Del matrimonio nacieron 3 varones y 2 mujeres; los primeros fueron Francisco y Bernardo, clasificados en un padrón de 1734 según sus "ocupaciones", uno como "traficante" y el otro como "navegante". Las prolijas investigaciones de Acuña no lograron más datos sobre esta familia; el silencio sobre los antepasados de don Luis y la imposibilidad de entroncarlos con estirpes mejor conocidas lo aproximan a sectores medios de la burguesía gaditana de aquel entonces, tal como las ocupaciones de su padre y sus hermanos parecen indicar.

La morada familiar en la puerta de embarque para las Indias seguramente impulsó el traslado del menor de los hermanos Díaz a estas tierras -con sólo 15 años- sin que tengamos noticias respecto de con quién vino o en qué circunstancias. Entre 1722 y 1738 Luis pasó su juventud en el Perú prestando servicios para señores, virreyes y gobernadores, "que todo consta por certificados de mis títulos", según informó en su testamento. ${ }^{2}$ Son casi 16 años sobre los cuales nada sabemos, pero sin dudas debieron ser tiempos de formación en oficios burocráticos y en cuestiones de gobierno. En 1739 lo encontramos en el Tucumán nombrado como gobernador de Armas de las ciudades de La Rioja y Catamarca, cargo que desempeñó durante 16 años, sumándosele incluso el gobierno de San Miguel de Tucumán, jurisdicción por entonces frontera de guerra.

La experiencia en el Tucumán debió ser capital para el diseño de sus proyectos: recorrió ciudades y campañas, reconoció sus potencialidades, recursos y oportunidades, ${ }^{3}$ se informó desde su lugar de autoridad y poder sobre cuáles eran las propiedades más importantes y en qué situación se encontraban, se vinculó socialmente con las elites con las que sin embargo no tramó relaciones de parentesco como otros funcionarios españoles lo hacían habitualmente. De hecho, y esta es otra peculiaridad del caso que tratamos, don Luis José Díaz jamás se casó y no se conoce que tuviera hijos naturales. ${ }^{4}$ No obstante, se integró al medio local al convertirse en encomendero de los pueblos de indios de Anguinán y Vichigasta, en la jurisdicción de La Rioja, y de Guaco -en el valle de Andalgalá- y Singuil -en la costa de Pomán- en la de Catamarca. ${ }^{5}$

En este período, y a pesar de las obligaciones de su cargo y de su protagonismo en la campaña militar a la frontera chaqueña (donde obtuvo el grado de teniente general), Díaz se mostró activo en el emprendimiento de "operaciones inmobiliarias": en 1743 compró a los herederos de los Nieva y Castilla (Cubas Palacio) la estancia de Huasán, que contaba con ganados, tierras destinadas al cultivo, casas de vivienda, molino, bodega y capilla. ${ }^{6}$ En breve, allí fijaría su morada principal a pesar de contar con casas en San Fernando del valle de Catamarca, Salta, La Rioja y en San Miguel de Tucumán. Adquirió la casa de Salta a través de una suerte de intercambio que realizó con los jesuitas de esa ciudad, a quienes entregó dos estancias, nombradas La Ollada y La Barrasa, sin que sepamos cuándo y cómo las había obtenido. En 1744 compró a los herederos de la familia Vega y Castro la estancia de Singuil ${ }^{7}$ (Guzmán, 1985; Bustos Argañaráz, 1987; Brizuela del Moral, 2003, p. 221) y al año siguiente legó a los jesuitas una hacienda -llamada El Colegio- situada en las 
cercanías de Andalgalá, todas ellas en Catamarca. Esta sería posteriormente un importante sostén para la obra evangelizadora que los jesuitas llevaron adelante entre los nativos del Chaco, frontera donde Díaz fundó un fuerte en 1752 (Acuña, 2016). ${ }^{8}$ En solo tres años Díaz había comprado extensas propiedades en la actual provincia de Catamarca, con la mira seguramente de hacer de ellas la base principal de sus emprendimientos agrícolas y ganaderos. ${ }^{9}$

Aunque no conocemos los valores de estas adquisiciones, otras cifras mencionadas en su testamento dejan pensar que Díaz manejaba buenos caudales cuando llegó al Tucumán; por ejemplo, la donación de $\$ 18.000$ para edificar la segunda Iglesia Matriz de la ciudad de San Fernando del Valle de Catamarca que fue inaugurada en 1744 . La estancia de Singuil le costó $\$ 17.500$ y, por supuesto, las donaciones realizadas a la orden jesuítica catamarqueña que según sus declaraciones ascendieron a $\$ 43.353$ (“de costo de principal de caudal de fincas de casas, haciendas de viñas y esclavos, estancias y ganados, iglesia y ornamentos y vasos sagrados, custodia, copón y demás menesteres"), amén de “más de $\$ 5000$ ” que les entregó en concepto de "socorros y donaciones". Cifras muy importantes salieron de sus bienes lo que hace pensar en emprendimientos exitosos, más aún si aceptamos su palabra de que hacia 1726 contaba apenas con \$2000 de caudal personal. ${ }^{10}$ Cuarenta años después la suya era quizá la fortuna más importante de la gobernación del Tucumán.

En su testamento encontramos referencia a otras propiedades: a media legua de Huasán, la hacienda de Santa Bárbara, alias La Toma; dos leguas "hacia abajo", la hacienda de San Pedro Nolasco, alias El Molino, a la cual expresamente declaraba que "no está inclusa en la institución del mayorazgo"; la estancia de las Minas y los potreros y estancia de Antofagasta. Esta última, su adquisición más tardía, fue otorgada en merced real por el gobernador Fernández Campero en 1766 con el objeto de activar la explotación del mineral aurífero de Nuestra Señora de Loreto o Ingaguasi, que estaba comprendido dentro de los límites de la merced (ver transcripción de la misma en Sánchez Oviedo, 1942). Así, Díaz proyectaba sus intereses en la minería que se extendían igualmente a otros emprendimientos más cercanos a su residencia. En 1762, por ejemplo, sabiendo de una próxima Visita Minera a realizarse en los alrededores del Aconquija, don Luis escribió al visitador invitándolo a pasar a su hacienda de Huasán, a que explorara especialmente los cerros cercanos proveyéndolo de todo lo necesario para el reconocimiento. ${ }^{11}$ En efecto, su testamento nos informa que en 1768 contaba con un trapiche en la quebrada de Choya, "que estoy fundando" dirá Díaz, "con todos sus peltrechos", y con un ingenio de moler metales adquirido a don Francisco Arias Rengel, ubicado en un lugar conocido como "Ingenio del Arenal", próximo a las minas del cerro Aconquija. Es decir, que el negocio minero estaba en marcha cuando Díaz dictó testamento ya que allí declaró haber formado con don Francisco Palencia "una compañía para la labor y trabajo de minas", contrato cuya escritura recomendaba cumplir proveyéndole de todo lo necesario ("se le haga todo el bien que posible sea").

Resta señalar que tal vastedad de propiedades era trabajada por un número poco certero de personal a su "servicio". Sabemos por el censo de 1771 (Acevedo, 1965), citado por la mayoría de los autores que se dedicaron a este tema, que en Santa Rita de Huasán vivían 117 personas, de las cuales 70 eran esclavos. Es una cifra significativa ya que Florencia Guzmán (2007) ha estimado la existencia de alrededor de 700 esclavos en la jurisdicción de Catamarca hacia 1778, ubicados en su mayoría en haciendas y estancias. Contaba además con mano de obra temporaria; los mitayos y tributarios de sus propias encomiendas -dos pueblos radicados en La Rioja y otros dos en Catamarca, como vimos- y trabajadores libres contratados por conchavos.

Por otro lado, desde 1760 don Bernardo Díaz de Peña, hermano mayor de don Luis, se encontraba en Catamarca y es muy probable que lo ayudara en la administración de los bienes y en la comercialización de la producción; fue su hombre de confianza a quien legó las rentas de su casa en Tucumán y pidió en su testamento que "no se le tome cuenta de nada de intereses, menos de los negros". Don Bernardo trajo de España a su sobrino, don Salvador Díaz de Peña, iniciándolo desde muy joven en las actividades mercantiles y en la administración de los bienes familiares.Juntos estuvieron en Buenos Aires, Tucumán y en Chile, donde don Salvador contrajo matrimonio. Ambos debieron incidir en la decisión de don Luis de solicitar las tierras 
de Antofagasta ya que fue don Salvador quien realizó la petición en su nombre y al ser concedida tomó la posesión a pedido de su tío.

En 1768, don Luis disponía la vinculación de la mayoría de las tierras a través del acta de fundación del mayorazgo, estableciendo el primer sucesor, el "orden de llamada" así como otras cláusulas fundamentales para el funcionamiento de esta institución como empresa. Las razones iniciales que adujo para esta decisión son las mismas que encontramos en otras fundaciones de mayorazgos; se trataba de evitar el menoscabo de los bienes que solía acaecer después del reparto del patrimonio entre varios herederos, llevando a la gente más ilustre a una irremediable pobreza. Dado que don Luis no tenía herederos forzosos pero sí varios hermanos, sobrinos y sobrinas, determinó -y en sus propias palabras- que "[queden] las haciendas en un solo poseedor, prohibida su enajenación, permanecen y duran, y teniendo con ellas lo que les basta se vive con grandeza y es perpetua la memoria de su sangre y casa" (Larrouy y Soria, 1921, p. 231).

Según Troisi Melean (2012) la decisión de fundar el mayorazgo de Huasán puede relacionarse con la expulsión de los jesuitas de 1767 ya que posiblemente Díaz tuviera la intención de donar todos sus bienes a la orden con la que tenía estrechos lazos. De ser así, la inesperada medida debió recordarle a Díaz la incertidumbre y los riesgos enfrentados por muchas familias y casas comerciales en contextos desfavorables a sus intereses. ${ }^{12}$ De ahí la frase de su testamento donde su espíritu emprendedor cede paso a un conservadurismo resignado: "he resuelto el instituir mayorazgo de mis bienes para que por lo menos ya que no se acrecienten, estén en un ser y valor" (Larrouy y Soria, 1921, p. 231). Por esta razón dispuso la realización anual de los inventarios como resguardo de los rendimientos productivos de sus bienes, responsabilidad asignada a cada titular.

El mayorazgo de Huasán estaba constituido entonces por las siguientes propiedades (ver Mapa 1): a) la hacienda de Santa Rita de Huasán, la estancia de Singuil y las tierras de Antofagasta; b) las casas de vivienda en las cuadras respectivas de las ciudades de San Fernando y San Miguel; y c) el trapiche situado en Choya y el ingenio ubicado en el Ingenio del Arenal. Es claro en este "armado" que las propiedades amayorazgadas, dispuestas en una amplia territorialidad discontinua, se complementaban a partir de sus diferentes orientaciones productivas: mientras que la hacienda estaba principalmente destinada al cultivo de cereales, algodón, vid y frutales variados (así como a la elaboración de aguardiente y vino), la estancia de Singuil era adecuada para la cría y el engorde de ganado vacuno y caballar. El trapiche y el ingenio en Choya así como la merced de Antofagasta estaban asociados a los emprendimientos mineros, aún en ciernes en este momento pero que prometían activar a futuro la economía de todo este complejo productivo. ${ }^{13}$

$\mathrm{Al}$ reunir estas propiedades y bienes bajo la imposición del mayorazgo que expresamente prohibía su división, don Luis José Díaz buscaba consolidar esa integración económica y productiva bajo el control de un solo titular, responsable de conducir el curso de esta empresa. El elegido para ocupar este rol fue su sobrino don Salvador Díaz, quien había sido debidamente preparado durante décadas para asumir esa responsabilidad. Es interesante notar que don Luis reservó una parte de sus bienes libres de esta institución, los que fueron igualmente heredados por don Salvador. ${ }^{14}$ Se trata de la hacienda San Pedro Nolasco, ubicada a pocas leguas de Huasán, el potrero de Las Minas y de una cuadra situada extramuros de la ciudad de Catamarca conocida como "La Quinta". ¿Cómo entender esta decisión consagrada en su testamento?

Posiblemente se trate de una estrategia para compensar los riesgos que las propiedades inmovilizadas por el mayorazgo solían comportar; frente a situaciones críticas la imposibilidad de vender los bienes por separado o la exigencia de invertir en la institución para evitar menoscabos daban poco margen de maniobra a los titulares, quienes como vimos estaban obligados a dar cuenta de todos los movimientos y operaciones realizados. Al poner a disposición de su sobrino este cúmulo de bienes productivos, don Luis resguardaba la opción de acudir a ellos libremente, cuando lo juzgara necesario. Veremos que si bien estos bienes "móviles" sirvieron para sostener el vínculo fueron también parte de la causa de su ruina ya que era la única porción de bienes que inicialmente los herederos podían disputarse. 


\section{El MAYORAZgo EN ACCióN}

En 1769, don Salvador Díaz asumía como primer titular del mayorazgo, por disposición de su tío quien aún vivió hasta 1772 (Bustos Argañaráz, 1979, p. 33; Vilgré La Madrid, 1977). A partir de esta fecha recibió también la segunda parte de su herencia consagrándose como un hombre rico y próspero. Debió cambiar su apellido por "Díaz de la Peña" según la voluntad de su tío, que los sucesores del mayorazgo debieron llevar (Acuña, 2016). Para ese entonces don Salvador vivía ya en la hacienda de Huasán y estaba perfectamente familiarizado con la dinámica de la administración del vínculo; contaba con apoderados, capataces y abogados a su servicio, además de una nutrida población de esclavos que él se ocupó de mantener y acrecentar.

Las pocas fuentes que hasta el momento encontramos sobre sus actividades lo muestran como un hombre de acción, llegado muy joven a América y dedicado desde entonces al trabajo y a los negocios que su tío había inaugurado. Antes de convertirse en Señor, don Salvador había logrado sus propios caudales que ascendían a \$11.618, que invirtió en el mayorazgo de Huasán a partir de 1769, dejando afuera unos pocos esclavos. ${ }^{15}$ El balance de sus actividades, esbozado en su testamento, permite inferir la importancia de las relaciones que mantenía con Chile -donde se había casado y continuaba residiendo su familia política-, con el Alto Perú, Salta y Buenos Aires; la actividad predominante parece haber sido la ganadería, un rubro en expansión a partir del último cuarto del siglo XVIII. En cambio, la minería aparece muy relegada frente a la producción de aguardiente, frutales y vides, y de hecho tanto el trapiche como el ingenio de moler metales se encontraban en ruinas a comienzos del siglo XIX. Es notable que siendo estos dos bienes consignados como parte del mayorazgo en 1768 no se haya pedido o rendido cuentas de lo que ocurrió con ellos décadas después; al parecer las actividades mineras quedaron desactivadas y las instalaciones simplemente fueron abandonadas ya que no podían ser vendidas.

Los esclavos fueron importantes capitales móviles en el complejo del mayorazgo. Como vimos, al realizarse la fundación vivían en la hacienda de Huasán 70 esclavos de distintas edades, número que su sucesor debió conservar. Don Salvador menciona varias operaciones de compra - venta de esclavos, reposiciones y reemplazos relacionados con "faltas de los mismos esclavos" (que decidían al señor a venderlos), o bien para reponer aquellos fallecidos o cedidos como adelantos de herencia de algunos de sus hijos. Los esclavos eran la fuerza de trabajo central del vínculo y la mayoría de ellos residía en la hacienda de Huasán, siendo su residencia "dos hileras de edificios con 24 aposentos o cuartos donde vive la esclavitud, cada uno de seis varas de largo con su puerta a una mano y las paredes de taperas, todos de media agua”. Eran también los servidores domésticos y acompañantes que connotaban el elevado status económico y social de los miembros de la familia Díaz de Peña. Y si bien don Salvador mantuvo la cantidad de esclavos afectados al vínculo, también contó con esclavos propios según declaró en su testamento; su valor oscilaba entre los 150 y los 200 pesos.

Las unidades productivas principales del mayorazgo continuaban siendo la hacienda de Huasán y la estancia de Singuil. Cuando en 1809 se procedió a los inventarios tras la muerte de don Salvador, los encargados de Singuil estuvieron contando ganado durante tres días. Había más de 500 terneros en pie, 240 terneros de más de 2 años, 162 vaquillonas, más de 1700 cabezas de ganado; el ganado caballar se componía de 440 yeguas, 120 caballos, 22 mulas, 47 potrillos y 14 burras. Estas cifras dan cuenta de la importancia de las actividades ganaderas en este período cuya integración a circuitos de intercambio regionales han sido analizados por Palomeque (2006). Los inventarios de Huasán son cuantiosos y su enumeración interminable; se destacan varias edificaciones antiguas y otras más nuevas destinadas a la residencia familiar, la iglesia de la hacienda, bodegas, galpones y salas de trabajo (herrería, carpintería, lagares y piletas, etc.), además de las viviendas de esclavos y servidumbre. Casi 20.000 cepas de vid, utilizadas para elaborar aguardiente y vino, se mantenían junto a árboles frutales numerosos y diversos (higueras, manzanos, granados, naranjos, limones, ciruelos, membrillos, perales), además de nogales, tunas, olivos y un algodonal. ${ }^{16}$ 


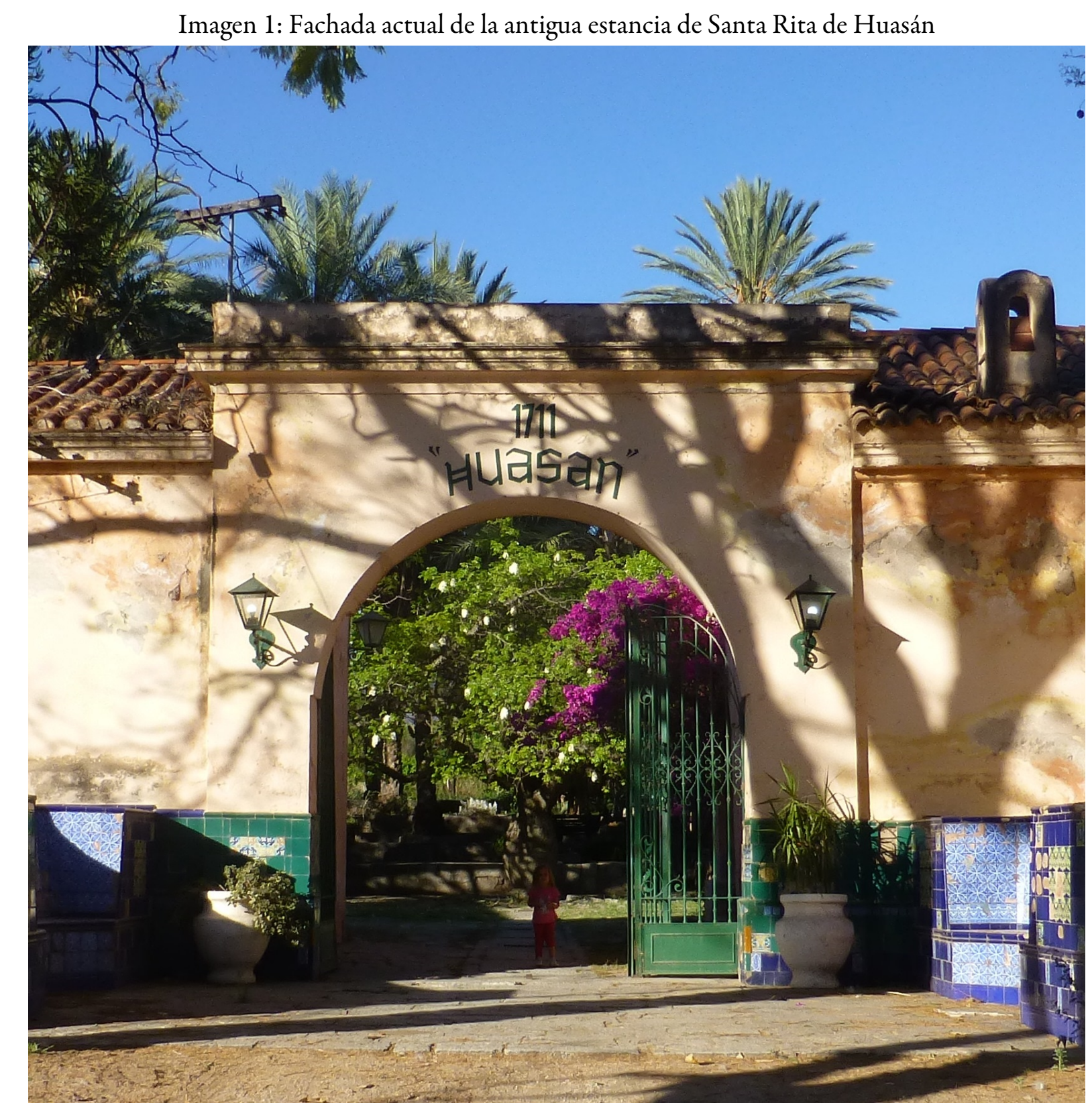

Fuente: Fotografía de las autoras, noviembre de 2018

Durante casi 32 años, entre 1769 y 1801, el mayorazgo de Huasán fue administrado por don Salvador Díaz de Peña, quien al redactar su testamento dejó en claro no deberle nada a nadie y, al contrario, haber invertido todo en el sostenimiento del vínculo. Por ejemplo, declaró haber vendido las propiedades en Salta, aquellas que su tío había adquirido a través de un trueque con los jesuitas junto con el engorroso pleito de 18 años planteado con la Junta de Temporalidades. El monto de esta venta $-\$ 3300$ - fue utilizado fundamentalmente para comprar esclavos que fueron incorporados al vínculo. Otros pasajes de su testamento dan cuenta de sus esfuerzos por mantener un regular control sobre sus propiedades y negocios a través de apoderados y representantes que por cartas le informaban del curso de las operaciones. Se mencionan compromisos de pago, cancelaciones, pérdidas de recibos, algunos con detalle porque se relacionaban con operaciones incompletas que quedarían en manos de su heredero.

A pesar de los varios apoderados que don Salvador menciona -representantes de sus intereses en las ciudades de Tucumán, Salta, en Chile y en Perú- y que debieron acompañarlo en el manejo integral del 
mayorazgo, al final de su vida dejó registro del peso que la administración de Huasán conllevaba. Con cierto desconsuelo declaró haberle entregado bienes al mayor de sus hijos, don Marcelo Antonio Díaz de Peña, al que había donado alhajas de plata, esclavos y otros bienes muebles cuando se casó, además de haberle entregado en otra oportunidad \$1200 en plata y oro. Sin embargo, este hijo no había cubierto sus expectativas. Al referirse a él asentó que "en todo ha caminado con desgracia y ninguna felicidad por no haberle ayudado la fortuna porque así le convendrá por cuyo motivo no ha podido ayudarme a mis adelantamientos por lo que he soportado personalmente el continuado remo de estas haciendas". La frase deja entrever al menos desacuerdos entre padre e hijo, que los habrían distanciado en el manejo común de las propiedades del mayorazgo. Y en efecto, Vilgré La Madrid (1977, p. 307) apunta que don Marcelo había iniciado una querella contra su padre por no haber realizado los inventarios anuales, por el deterioro que afectaba a algunos de sus bienes y por no haber solicitado la confirmación real del mayorazgo. Esto sucedía en 1792, pocos años antes de redactar su testamento.

Además de esta discordia con su hijo, don Salvador había enfrentado en 1789 otro conflicto que lo había expuesto públicamente: fue denunciado por el cura párroco de Belén -en representación de varios vecinos y parientes del mayorazgo- por llevar una vida disoluta y licenciosa puertas adentro de su hacienda, con "desenfrenada lascivia hasta el último extremo sin exceptuar las propias esclavas que tiene en su casa” (citado en Acuña, 2016). El gobernador Andrés Mestre minimizó el tono del escándalo señalando que los denunciantes eran enemigos de don Salvador y que querían exponerlo. Su esposa vivía en la casa que el mayorazgo tenía en Tucumán, habiendo abandonado la hacienda en 1782. El episodio lo retrata como un ser déspota acostumbrado a hacer su voluntad en su pequeño universo que era Huasán, donde vivió sus últimos años retirado.

Su fallecimiento se produjo en 1801 y al año siguiente su hijo don Marcelo tomó posesión del mayorazgo. Solicitó la apertura de la sucesión de los bienes personales de su padre y el inventario de los bienes para poder distinguir cuáles pertenecían al mayorazgo y no podían ser repartidos entre los herederos. En la misma presentación ante el cabildo renunció a la herencia paterna dada su condición de sucesor del vínculo, si bien por las particiones que se realizaron en 1809 sabemos que tuvo acceso a la misma en igualdad de condiciones que los demás coherederos. Durante casi 8 años la familia Díaz de Peña se vio envuelta en los complejos y conflictivos trámites de las partijas que comenzaron con los reclamos presentados en nombre de don José Fermín de Molina y Díaz de Peña, hijo único de doña Agustina Díaz de Peña y nieto de don Salvador. El caso es que en su testamento doña Agustina fue citada entre los hijos ya fallecidos pero no mencionó la existencia de un heredero. ${ }^{17}$ Esto derivó en un pleito que terminó gracias a un acuerdo entre las partes alcanzado en 1808 , en el que don Marcelo debió pagar a su sobrino $\$ 1200$ en compensación, para luego reconocerlo como heredero.

Los inventarios y partijas judiciales llevadas adelante en 1809 determinaron que los bienes libres o "líquido caudal para partirse" ascendía a la suma de $\$ 25.000$, que fue repartida entre 5 herederos, uno de ellos era la viuda de don Salvador, quien recibió además $\$ 5720$ de gananciales. La mayor parte de estas hijuelas fueron pagadas en bienes - poco en dinero líquido-, distribuyéndose todo lo que estaba disponible y que hubiera sido tasado, desde esclavos hasta muebles, lienzos y cuadros, libros, vajilla, cajas, imágenes de bulto, armas, aguardiente, algodón, entre muchos otros objetos variados (ropa, sombreros, espejos, alhajas, cuchillos, etc.).

Finalizadas las partijas todos los herederos firmaron su aprobación en Huasán el 31 de agosto de 1809. Si bien don Marcelo había logrado sortear los difíciles desafíos del proceso de sucesión y herencia, la historia política iba a imponerle nuevos retos a partir de 1810; mantuvo sus actuaciones en el cabildo de Tucumán entre 1815 y 1816, siendo elegido regidor decano o alférez de la Patria. Integró igualmente las tropas que se dirigieron a Salta como parte de las campañas al Norte, con el grado de capitán (Acuña, 2016). Su fallecimiento en 1822 marca el inicio de otra etapa en el vínculo y en la familia Díaz de la Peña. 


\section{LOS RIESgOS DE UNA INSTITUCIÓN COMPLEJA: EL DEVENIR DEL MAYORAZgo DURANTE EL SIGLO XIX}

A partir del tercer mayorazgo creemos se produjo un verdadero punto de inflexión en el devenir de la institución de Huasán. Si bien previamente, como acabamos de ver, se habían originado diversos conflictos entre los integrantes de la familia, así como coyunturas económicas y políticas que afectaron su desarrollo, será recién a partir de la segunda o tercera década del siglo XIX que el mayorazgo será "puesto en jaque", comenzando así un derrotero inexorable hacia su definitivo ocaso (no necesaria o exclusivamente asociado a la ola desamortizadora propia de ese momento).

El tercer titular del vínculo fue don Miguel Díaz de la Peña (nieto del primer instituido, don Salvador Díaz de la Peña e hijo legítimo de don Marcelo Díaz de la Peña y de doña Josefa Figueroa). Nacido en Tucumán en 1795, había desarrollado una importante carrera política a lo largo de su vida. Fue cabildante en San Miguel de Tucumán, capitán de milicias en 1812, miembro del Partido Unitario y diputado en el Congreso Nacional de 1824 que sancionó la constitución que llevó al poder a Bernardino Rivadavia. Poco tiempo después, en 1830, fue gobernador de Catamarca, aunque al año siguiente fue derrocado por las fuerzas del federal Facundo Quiroga y tuvo que exiliarse primero a Ecuador y luego a Bolivia (Vilgré La Madrid, 1977; Bustos Argañaráz, 1979; Acuña, 2016).

Antes de este hecho, si bien es posible rastrear en el archivo local (AHC) algunos pleitos, la situación del mayorazgo parecía ser bastante estable y económicamente rentable, tal como ha sido descripto en el apartado anterior. Inclusive, aunque la explotación minera dentro del mayorazgo se había desarticulado tempranamente durante el período colonial, había sido retomada por don Miguel bajo el impulso que primero siendo Ministro de Relaciones Exteriores y luego Presidente- había dado Rivadavia a la reactivación de la actividad a través de negociaciones con capitales extranjeros (Catalano, 2004). De Moussy (1860) describe que en 1825 don Miguel hizo traer 28 mineros ingleses, restauró las instalaciones y los molinos con el objetivo de procesar el mineral - por trituración y amalgamación- que extraía de la sierra de Aconquija, pero al poco tiempo todo el emprendimiento minero se desactivó nuevamente en el contexto de las luchas entre unitarios y federales. En términos generales, podemos decir que a partir de 1830 los conflictos dentro del mayorazgo empezaron a desencadenarse y complejizarse en relación con diferentes frentes.

Recordemos que don Miguel tuvo que exiliarse en 1831, dejando todos los bienes del mayorazgo que, como señala Vilgré La Madrid (1977), no le fueron confiscados, pero por los cuales debía velar, aunque más no fuera a la distancia. Esta situación abrió una primera etapa de conflictos con varias aristas, pero centrados en la ausencia del titular y su imposibilidad de ocuparse personalmente de los "negocios" familiares. Al respecto, disponemos de documentación que nos habla de las tensiones entre don Miguel y quienes funcionaron como administradores del mayorazgo. Por ejemplo, la que se produjo entre don José María Figueroa Usandivaras, que no era ni más ni menos que el hermano menor de un cuñado suyo (esposo de doña María del Rosario Díaz). En un folleto de autor anónimo fechado en 1854, atribuido por Acuña (2016) al propio Miguel, ${ }^{18}$ este daba cuenta de dicho conflicto. Allí mencionaba que, desde Guayaquil, había celebrado en 1845 un contrato con don José María “en virtud del cual se comprometió a administrar la finca de Huasán” y denunciaba, como "patrón" que era, que Figueroa no había remitido a Guayaquil el dinero correspondiente a la administración de Huasán. La muerte de Figueroa en 1848 y el traspaso de la tarea a otra de sus hermanas, doña Cruz Díaz, no liquidaría los conflictos por la administración.

En 1850, esta última era acusada por don Miguel de haber "abandonado absolutamente el cuidado de las fincas, cuya elaboración y consiguientes trabajos se hallan enteramente paralizados, desconociendo al mismo tiempo el deber de entregar la administración como el de darle cuenta y razón"; ${ }^{19}$ por tal motivo le solicitaba a María del Rosario se ocupara del asunto para poner las cuentas en orden. No olvidaba, don Miguel, los conflictos previos que había tenido con ella y el hermano de su esposo (el anterior administrador) pero la necesitaba para que todo se encauzara. ${ }^{20}$ Lo interesante de este expediente sobre el que vale la pena detenernos 
es que, además de dar cuenta del conflicto por la administración, incluye un nuevo inventario de los bienes vinculados realizado en 1851, dándonos idea de la esfera productiva del mayorazgo por aquellos años.

En la propia hacienda de Huasán, además de la casa en sí con todos sus bienes y otras instalaciones contiguas, el inventario nos muestra que fundamentalmente allí seguía elaborándose vino, aguardiente y "otros licores" pues se registraron varios elementos para su producción y guardado; también se destaca la huerta con gran cantidad y variedad de árboles frutales (naranjos, nogales, ciruelas, limas, granadas, además de las viñas) y la producción de maíz, trigo y porotos. En la hacienda del Molino, que a esta altura se registró como parte del mayorazgo, aunque inicialmente como señalamos habría sido externa al mismo, los elementos inventariados dan cuenta también de la producción vitivinícola y agrícola (en este último caso se mencionan rastrojos de arrenderos) y de la presencia de árboles frutales. Se destaca especialmente "el molino de moler" en buen estado, junto con todas sus herramientas, que probablemente se utilizaba para elaborar harinas. Es interesante notar que si bien se registró un potrero "a la cabeza de los terrenos de la hacienda" prácticamente en el inventario no se enumeraron animales. Asimismo, aunque se anotó la "estancia de Singlis [Singuil?] con sus terrenos de labranza”, llamativamente tampoco se inventarió animal alguno.

Respecto a los conflictos que hubo de enfrentar don Miguel desde el exilio podemos mencionar también los dos pleitos con su propia madre - doña Josefa Figueroa- que llegaron a ventilarse en la justicia catamarqueña. Doña Josefa, a través de su hija María del Rosario, que funcionó como apoderada, le hizo a don Miguel dos reclamos puntuales. El primero, del año 1845 , solicitándole le reintegrara una suma de dinero relativa a la venta que -sin su consentimiento- don Miguel habría efectuado en 1830 de una casa de doña Josefa sita en la ciudad de San Miguel de Tucumán (Acuña, 2016). El segundo, de 1847, en el que ella le requería el suministro de alimentos. ${ }^{21}$ Ahora bien, como el folleto antes mencionado nos deja entrever, los conflictos de don Miguel eran muchos y variados. Entre las tensiones ocurridas con sus familiares más directos podemos agregar - sin mayores datos por el momento- la que aparentemente tendría con su prima Petrona Boter "a quien se le antojó poseer la hacienda nombrada Jumalao [Julumao]" (ella luego sería una de las pretendientes del mayorazgo). Otro de los conflictos lo habría tenido con don Manuel Malbrán, acusado de adueñarse de unas minas de cobre de propiedad de don Miguel. ${ }^{22}$ En dicho folleto, además, a la luz de las descalificaciones que pesaban sobre algunos jueces locales (Benedicto Ruzo, Vicente Molas) y sobre el propio gobernador de la provincia (Manuel Navarro) podemos vislumbrar el amplio espectro de problemas a los que debía enfrentarse, a la distancia, el tercer instituido.

Una segunda etapa de conflictos -asociada a la herencia del vínculo y tal vez el definitivo punto de inflexión del mayorazgo- se inició con la muerte de don Miguel en 1855, año en que se presentó ante la justicia doña Josefa María Cabero alegando que era casada (por poder) con don Miguel y que tenía una hija (doña Elisa Díaz de la Peña) que era la heredera legítima del mayorazgo. Prontamente, doña Josefa (como curadora de doña Elisa que era menor de edad) se puso al frente de dicha institución. Ese mismo año -a través de un apoderado- solicitó que el poder ejecutivo federal (que en aquel momento tenía como presidente de la Confederación a don Justo José de Urquiza) les concediera permiso para desvincular algunas propiedades del mayorazgo, aduciendo que "ha[bía] sido entregado con faltas", que se había disminuido quizás a la mitad del valor original y "que para atender a su estado ruinoso y mejorarlo convendr[ía] la enajenación de algunas heredades correspondientes a él”. ${ }^{23}$ El ejecutivo nacional contestó que no era un tema de su incumbencia y correspondía al poder provincial dictaminar en el asunto ${ }^{24}$ y así es como doña Josefa decidió acudir -en primer término - a la justicia tucumana. Levaggi (2012) da detalles de esta solicitud y nos informa acerca de que previamente en 1852, don Miguel desde el exilio, había solicitado el mismo permiso, pero sin éxito. ${ }^{25}$ En septiembre de 1856, en cambio, la petición de doña Josefa fue aprobada por la Sala de Representantes de Tucumán. ${ }^{26}$

En 1857, doña Elisa (que aún era menor pero ya estaba casada con el médico inglés Enrique Priestley) logró también desvincular otra de las propiedades del mayorazgo, la estancia de Singuil, vendiéndola entre 
diciembre de 1857 y noviembre de 1858 a dos destacadas figuras del espectro político local (don Samuel Molina y don Manuel Navarro), seguramente en base a resoluciones previas de la legislatura de Catamarca que así lo autorizaba a fin "de reparar y mejorar la parte restante del mayorazgo". ${ }^{28}$ Ese mismo año y como parte de las atribuciones asumidas prontamente por doña Josefa a nombre de su hija, también se ocupó de arrendar la denominada Hacienda del Molino a don José Luis Quiroga (contrato que de todos modos sería prontamente rescindido por su flamante yerno por considerar este que sus condiciones iban "en detrimento... de los intereses del mayorazgo de Guazán"). ${ }^{29}$

¿Cuáles eran las motivaciones de las rápidas acciones de Josefa y su yerno para con los bienes del mayorazgo? ¿Era cierto que el valor del mismo se hallaba tan disminuido, que se encontraba en ruinas y se había tornado improductivo? ¿O era una mera excusa para hacerse rápidamente de dinero en un contexto que, como veremos a continuación, no sería favorable a ellos para siempre? ¿Podría pensarse, en cambio, que la reciente instituida y sus curadores buscaban iniciar una nueva etapa del mayorazgo, reorientando una vez más el proyecto económico e invirtiendo parte de lo obtenido de la desvinculación de bienes y arriendos en la vieja institución con el único fin de renovarla? Las distintas interpretaciones son posibles y no excluyentes. El mayorazgo, después de todo, había probado ser bastante rentable y flexible a lo largo del tiempo, pero la situación de doña Elisa al frente del mismo era endeble, como pronto quedó en evidencia.

En 1858 don Hilario Molina, nieto de doña Agustina Díaz de la Peña y bisnieto de don Salvador Díaz de la Peña, inició un juicio en Catamarca para demostrar que Elisa no era la legítima sucesora y reclamar se lo instituyera a él como el siguiente mayorazgo; ${ }^{30}$ nombramiento que logró, no sin conflictos, recién en 1863 cuando finalmente fue declarado como quinto y último mayorazgo de Huasán. ${ }^{31}$ En el transcurso de los años en que duraron los juicios de sucesión, tanto la parte de Molina como la de Elisa aseguraron aunque con distintos fines- que el vínculo se hallaba disminuido. En uno de los expedientes, por ejemplo, el apoderado de Molina mencionaba la "dilapidación cuatrienal del mayorazgo" en referencia a que no sólo se habían vendido, como ya vimos, los sitios y casas en Tucumán (que él valuaba en 9 mil pesos) y la estancia de Singuil ( 8 mil pesos) sino que, además, se habrían esfumado 15 mil pesos correspondientes a arriendos y a la venta de frutos, enseres y vasijas de la hacienda. Al respecto insistía en que la "disipación" era consecuencia de "las extracciones tan públicas como escandalosas que esta mujer audaz [Josefa Cabero] ha hecho de muchos útiles y muebles de dichas haciendas". ${ }^{32}$ De la parte de Elisa se argumentaba, en cambio, que Molina "no habiendo investido otro carácter que el de arrendatario, dilapidador de intereses ajenos y moroso en su pago... [buscaba] eternizar el litigio y hacer efectiva la ruina de los bienes en que consiste el mayorazgo". ${ }^{33}$ La guerra había sido declarada y se desarrollaba en distintos episodios (solicitudes de embargos, denuncias de robo, acusaciones de inmoralidad); pero tarde o temprano llegaría a su fin.

Cabe destacar que, a pesar de las "disipaciones" mencionadas, la hacienda de Huasán propiamente dicha seguía en pie y constituía un claro punto de interés para las partes que disputaban la sucesión del que había sido (¿o era?) tan "pingüe y valioso" mayorazgo. Un dato al respecto es que, cuando en el año 1858 las partes acuerdan - por extraña sugerencia de Priestley- dejar en depósito los bienes hasta que se resuelva el pleito y nombrar un administrador con la potestad de trabajar las haciendas por sí o por terceros, ${ }^{34}$ fueron varios los interesados en el arrendamiento de la propiedad de Huasán, siendo don Hilario (a través de su apoderado don Vicente Bazán) el que finalmente se viera beneficiado con esta opción asociándose tiempo después para el trabajo de la hacienda con el reconocido abogado tucumano don Vicente Lezana. ${ }^{35} \mathrm{El}$ arriendo nunca fue pagado por Hilario ${ }^{36}$ y desató un conflicto que hizo que la suerte se inclinara nuevamente hacia doña Elisa, pasando a mediados de 1860 el mayorazgo a su órbita. La justicia ordenó entonces que tanto los arrenderos y subarrenderos de Huasán como los de la finca del Molino la respetaran a ella o sus representantes como "verdaderos dueños y poseedores". ${ }^{37}$ A tal fin se practicó un nuevo inventario. En Huasán, esta vez, algunos animales que se habían esfumado previamente volvían a aparecer. Sin embargo, la producción de vinos, aguardientes, cereales y frutas seguía caracterizando el perfil de la hacienda. Don Hilario aducía que había 
realizado importantes mejoras y volvía a insistir en sus derechos. Así es como logró finalmente que el 2 de junio de 1862 el juez local revocara la orden que nombraba a Elisa titular del mayorazgo pasando por fin a sus manos, fallo confirmado por la Cámara de Justicia el 22 de enero de $1863 .^{38}$

Pero la suerte de don Hilario sería breve. Además de otros conflictos que hubo de enfrentar (sobre los que ya no podemos profundizar), ${ }^{39}$ la muerte temprana de su hijo mayor -en quien había depositado el manejo del mayorazgo y quien era el legítimo heredero del mismo- volvió a ponerlo en una situación delicada. Su nuera se negaba a restituirle los bienes y es así como don Hilario, en el marco del juicio que se llevó a cabo, solicitó en 1869 la total y definitiva desvinculación de los mismos. El 5 de noviembre de ese año la Legislatura de Catamarca hizo lugar a la solicitud y fue así como, después de un largo siglo, el famoso mayorazgo de Santa Rita de Huasán se extinguió definitivamente (Bustos Argañaraz, 1979), dando inicio a una nueva etapa en la zona. Tal como expresaba Samuel Lafone Quevedo:

La fortuna de los Diaz de Huasan desapareció y muchas otras con ella, mas de sus cenizas se levantaron otras, y con la fundación de la Villa del Fuerte de Andalgalá, a mediados de este siglo, y en terrenos del pueblo de Huachaschi, se inició la nueva era de este lugar, que espera con ansias la llegada de la vía férrea para desarrollar su riqueza minera y agrícola (Lafone Quevedo, 1888, p. 103).

\section{Conclusiones}

A partir de esta aproximación preliminar a la historia del mayorazgo de Huasán podemos avanzar algunas conclusiones provisorias con vistas a continuar profundizando el análisis. Partimos de la hipótesis de que este mayorazgo respondió a un diseño empresarial que articulaba diferentes especializaciones productivas y el manejo simultáneo de propiedades indivisas y libres. Los bienes libres servían como recursos móviles a los que los titulares del mayorazgo podían recurrir para sostener la integridad y capacidad productiva del vínculo que, preservado de la división por cláusulas de institucionalización, constituían la base material del patrimonio familiar inalterable. Durante la etapa colonial este esquema dio buenos resultados, generando al señor del vínculo y a sus familiares directos grandes beneficios económicos. Los conflictos suscitados al interior del grupo familiar - las demandas de don Marcelo a su padre por inventarios no realizados, y el proceso sucesorio tanto del mayorazgo como de los bienes libres de don Salvador- no impactaron sobre el conjunto productivo que continuaba dando muy buenos dividendos, salvedad hecha de las explotaciones mineras que estaban prácticamente abandonadas a comienzos del siglo XIX. Una segunda lectura de los inventarios y de la sucesión de los bienes de don Salvador (tanto del mayorazgo como de los bienes libres) permite advertir que más allá de ciertas omisiones o silencios, sus herederos -mujer e hijos, representantes de un nieto menor- acordaron el modo más ecuánime y conveniente de repartirse entre todos su patrimonio personal preservando los bienes vinculados bajo la administración de don Marcelo.

El advenimiento del período independiente, pero sobre todo conflictiva guerra civil, que deparó casi 25 años de exilio a don Miguel, signó el inicio de los mayores desafíos para el mayorazgo. Fueron vanos todos sus intentos por dirigir la administración de sus propiedades desde el exilio (Potosí, Guayaquil); sus cuñados, hermanas, administradores varios -y posiblemente otros deudos- aprovecharon su prolongada ausencia para drenar recursos y beneficios generados por el vínculo.

Si comparamos los bienes consignados en la testamentaria y en la sucesión de don Luis José Díaz (1769), de don Salvador Díaz de Peña (1799 y 1809, respectivamente) con los que aparecen en disputa a partir de 1855, después de la muerte de don Miguel Díaz de la Peña, surgen diferencias que merecen atención. Por ejemplo, la enorme merced de tierras de Antofagasta parece haber desaparecido de los registros del mayorazgo ya en 1809 , sin que sepamos cuál fue su destino. ${ }^{40}$ Otras propiedades, como la hacienda de El Molino y Julumao, cumplieron el rol de bienes móviles incorporados al mayorazgo para ser protegidos o para compensar pérdidas económicas. ${ }^{41}$ Sobre las actividades mineras, reactivadas por don Miguel antes de 
exiliarse, tampoco quedaron referencias precisas; recién en la última etapa de los conflictos sucesorios -a partir de 1860 - se advierte la presencia de nuevos personajes interesados en los avances de la desvinculación que darían vía libre al acceso a las tierras valoradas en relación con la actividad minera en la zona que estaba alcanzando su momento de mayor producción. Al respecto, es elocuente la carta que escribe el 6 de noviembre de 1869 el administrador de la empresa minera La Restauradora (Juan Heller) al dueño de la misma (Lafone Quevedo):

Me han asegurado que han logrado desvincular a Guazán, 1/4 parte queda para el hijo de Miguel y el resto para Don Hilario; que no creo alcanzará a mas que cubrir las deudas que tienen y quien sabe los pleitos que están para entablarse. No perderé de vista el Puesto y Molino si algo se puede hacer y con seguridad. ${ }^{42}$

En efecto, sabemos que Lafone Quevedo compró e integró a su complejo minero varias propiedades que pertenecían al antiguo mayorazgo de Huasán. ${ }^{43}$

Por cierto, que las fuentes que hasta ahora manejamos nada dicen respecto de la importante población de esclavos que trabajaban en las haciendas y estancias amayorazgadas; es posible que algunos de ellos se hubieran reconvertido en los peones que aún vivían y trabajaban en Huasán mientras los litigios se sucedían. Otro rubro ausente de los registros decimonónicos es el ganado; el significativo número de cabezas ovino y caballar además de las mulas y el ganado menor consignado en 1809 pudo ser objeto de periódicas requisas durante las guerras, contribuyendo a su disminución -o quizá a su ocultamiento-; este tema requiere ser investigado recurriendo a otras fuentes. Por lo pronto, nuevamente las palabras de Juan Heller escritas el 20 de noviembre de 1869 a propósito del interés en las propiedades que estaban desvinculándose, nos ofrecen algunas pistas: "Están bajando las acciones de Guazán; acabo de recibir una carta de Don Hilario que está tratando de vender sus bueyes y mulas como en tiempos de revueltas, para que no se las quiten". ${ }^{44}$

Es posible que después de la muerte de don Miguel sus conflictivos herederos hayan intentado recuperar en parte la estructura que combinaba bienes libres y amayorazgados para refuncionalizar la alicaída institución. Ya este había recurrido a la estrategia de vincular la estancia de El Molino, un bien personal. Su viuda, doña Josefa, procederá a arrendar esta estancia al tiempo que su hija y heredera, doña Elisa, desvinculaba la estancia de Sínguil principal productora de ganado, para venderla en 1857, con el fin de "reparar el mayorazgo". ¿Sería este su objetivo? ¿Buscaban el beneficio propio o hacerse de medios para enfrentar los litigios que se avecinaban? No tenemos respuestas claras a estos interrogantes, pero no escapaba a estas mujeres -ni a Priestley y sus socios- que continuaba siendo importante preservar la hacienda principal, Santa Rita de Huasán, la que a pesar de todo aún era productiva y rentable. No en vano, el propio Heller en 1866 en referencia a un potrero que daba buenos pastos utilizaba la expresión de "vale un Huasán". ${ }^{5}$

Finalmente, es claro que el mayorazgo se tornó en una institución inviable debido a la continua litigiosidad que su sucesión provocó entre los descendientes de don Luis José Díaz, ocasionando importantes erogaciones. La falta de primogénitos varones abrió la compulsa sobre quién tenía "mejores derechos” en un contexto donde las antiguas cláusulas que lo habían regido - por ejemplo, el "orden de llamada" - ni siquiera eran invocadas como argumentos de peso. Ni los litigantes ni quienes los representaban parecían recordar, en medio de los complejos pleitos que se ventilaron en los juzgados durante más de una década, que la venta de alguna de sus partes sin reponer el capital inicial ponía al mayorazgo en jaque y al borde de su desarticulación. Y aunque la legislación indiana preveía el derecho a enajenar algunos bienes para mantener el valor de la dotación inicial ${ }^{46}$-lo que exigía licencias y buenas fundamentaciones-, en el contexto decimonónico había ya un nutrido conjunto de parientes a quienes no alcanzaban los bienes partibles y buscaban acceder, de a poco y a través de pleitos, al corazón del mayorazgo. También en este siglo los derechos a la herencia distributiva ganaron espacio frente a la unigenitura arquetípica del mayorazgo, cuestión plasmada en el nuevo código civil del país de 1871. 
Roxana Boixadós, et al. Una hacienda en JaQue: el Mayorazgo de Huasán y los desafíos de las trans...

\section{REFERENCIAS}

Acevedo, E. (1965). Situación social y religiosa de Catamarca en 1770-1771. En Primer Congreso de Historia de Catamarca. Tomo Segundo (pp. 23-98). Catamarca: Junta de Estudios Históricos de Catamarca.

Acuña, S. E. (2016). Los Díaz de Peña. Un mayorazgo, varios problemas sociales y genealógicos. Revista del Centro de Estudios Genealógicos y Heráldicos de Catamarca, 5.

Artís Espriu, G. (1994). Familia, riqueza y poder. Un estudio genealógico de la oligarquía novohispana. México: Centro de Investigaciones y Estudios Superiores en Antropología Social.

Beceiro Pita, I. y Córdoba de la Llave, R. (1990). Parentesco, poder y mentalidad. La nobleza castellana, siglos XII-XV. Madrid: Consejo Superior de Investigaciones Científicas.

Boixadós, R. (1999). Transmisión de bienes en familias de elite: los mayorazgos en La Rioja colonial. Andes, 10, 51-78.

Boixadós, R. (2001). "Cuñados no son parientes sino accidentes." Conflictos familiares en torno a la herencia de Cochangasta (La Rioja, siglo XVIII). Anuario, 1(1), 39-60.

Brizuela del Moral, F. (2003). Historia de las Mercedes de tierra en Catamarca. Siglos XVI al XIX. Catamarca: Universidad Nacional de Catamarca.

Bustos Argañaráz, C. P. (1979). Crónica Genealógica del Mayorazgo de Huasan. Revista del Centro de Estudios Genealógicos de Buenos Aires, 1, 29-39.

Bustos Argañaráz, C. P. (1987). Crónica de Singuil y sus propietarios. Revista del Junta Provincial de Historia de Córdoba, 12, 175-202.

Catalano, E. (2004). Antecedentes y estructura histórica de la minería argentina. En E. Lavandaio y E. Catalano (Eds.), Historia de la minería argentina (Tomo 1, pp. 1-176). Buenos Aires: Servicio Geológico Minero Argentino.

Clavero, B. (1974). Mayorazgos. Propiedad feudal en Castilla. 1369-1836. Madrid: Siglo XXI.

Cramaussel, C. (2010). Valerio Cortés del rey, fundador del único mayorazgo de la Nueva Vizcaya en el siglo XVII. Revista de Indias, 70(248), 77-100.

De Moussy, M. (1860). Description géographique et statistique de la Confédération Argentine, Tomo Segundo. París: Librerie de Firmin Didot Frères.

De la Orden de Peracca, G. (2016). Familia, mayorazgo y tierras en Catamarca. Siglos XVIII a XX. Boletín Digital de la Academia Nacional de la Historia de la República Argentina, 27, 34-41.

Doucet, G. (2006). Los Campero y el Marquesado del Valle de Tojo. Revista Fundación Campero, 1, 1-8.

Farberman, J. y Boixadós, R. (2015). Mayorazgos, pueblos de indios y campos comuneros: la propiedad indivisa en La Rioja (siglos XVII-XIX). Revista de Ciencias Sociales, 27, 19-45. Recuperado de http://www.unq.edu.ar/catalo go/357-revista-de-ciencias-sociales-n-27.php

Fernández de Recas, G. (1968). Mayorazgos en la Nueva España. México: Instituto Bibliográfico Mexicano.

Fernández Pérez, P. (1997). El rostro familiar de la metrópoli: redes de parentesco y lazos mercantiles en Cádiz, 1700-1812. Madrid: Siglo XXI de España Editores.

Gómez Serrano, J. y Delgado Aguilar, F.J. (2006). Un mayorazgo sin fundación. La familia Rincón Gallardo y su latifundio de Ciénaga de Mata, 1593-1740. ICA: Universidad Autónoma de Aguas Calientes.

Gómez Serrano, J. (2017). La hacienda de Ciénaga de Mata, desde su formación hasta el fin de la reforma agraria. América Latina en la Historia Económica, 24(3), 130-160.

Guzmán, F. (2007). Africanos y descendientes en Catamarca: una mirada local y regional de fines de la colonia. En Tercer Congreso de Historia de Catamarca, Tomo II: Historia Politica e Institucional. Sociedad, Población y Economia (pp. 263-286). Catamarca: Editorial de la Universidad Nacional de Catamarca.

Guzmán, G. (1985). Historia Colonial de Catamarca. Poblamientos, fundaciones y desenvolvimiento social. Catamarca: Editorial Milton.

Ladd, D. (1986). La nobleza mexicana en la época de la Independencia 1780-1826. México: Fondo de Cultura Económica. 
Lafone Quevedo, S. (1888). Londres y Catamarca. Cartas a La Nación. Buenos Aires: Imprenta y Librería Mayo.

Larrouy, A. y Soria, M. (1921). Autonomía Catamarqueña. Homenaje en su primer centenario. Buenos Aires: Imprenta D'Amico Hermanos y Talleres Gráficos Peuser.

Levaggi, A. (2012). Desvinculación y venta de fundos tucumanos del mayorazgo de Guazán (1852-1856). Épocas. Revista de Historia, 6, 123-135.

Madrazo, G. (1990). Hacienda y encomienda en los Andes. La Puna argentina bajo el marquesado de Tojo, Siglos XVII a XIX. Jujuy: EdiUNJu.

Mariluz Urquijo, J. (1970). Los mayorazgos. Lecciones y ensayos, 42, 55-77.

Núñez Moreno, J. (1984). Mayorazgos arcaicos en Castilla. En la España medieval, 5, 693-706.

Palomeque, S. (2006). Circuitos mercantiles de San Juan, Mendoza y San Luis. Relaciones con el “Interior Argentino", Chile y el Pacífico Sur (1800-1810). Anuario IEHS, 21, 255-286.

Presta, A. M. (1999). Mayorazgos en la temprana historia de Charcas: familias encomenderas en La Plata, siglo XVI. Revista Genealogía, 59(30),140-154.

Quesada, M. y Lema. C. (2011). Los potreros de Antofagasta. Trabajo indígena y propiedad (finales del siglo XVIII y comienzos del XIX). Andes. Antropología e historia, 22, 1-21.

Quintanilla Raso, M. C. (2004). Propiedad vinculada y enajenaciones. Métodos y lógicas nobiliarias en la Castilla tardo medieval. Historia, Instituciones, Documentos, 31, 493-500.

Rangel, E. (2013). El Mayorazgo de Sartenejes en la Venezuela colonial. Historia y Memoria, 6, 17-39.

Rodríguez, L. (2017). Mayorazgo y minería en Catamarca. Primeras reflexiones sobre la desamortización y la modernización en la segunda mitad del siglo XIX. Ponencia presentada en Seminario Internacional Derechos colectivos e individuales en torno a los recursos naturales, siglos XVIII-XIX (11 y 12 de septiembre de 2017). Bernal: Universidad Nacional de Quilmes.

Rojas, F. (2013). Rol de la minería y el ferrocarril en el desmonte del oeste riojano y catamarqueño (Argentina) en el período 1851-1942. Población \& Sociedad, 20(1), 5-39.

Sánchez Oviedo, C. (1942). Los derechos de Catamarca a la Puna de Atacama. Boletin de la Junta de Estudios Históricos de Catamarca, 2(1), 17-33.

Serrano Redonnet, J. (1992). La sociedad de Buenos Aires en sus derechos a mayorazgos y a otras fundaciones españolas. Buenos Aires: Academia Americana de Genealogía.

Smietniansky, S. y Boixadós, R. (2015). Tiempo y parentesco. Una propuesta para el estudio del mayorazgo en el Tucumán colonial. Ponencia presentada a la XI RAM, Montevideo.

Tarnassi, A. y Domínguez, J. (1884). Fallos de la Suprema Corte de Justicia Nacional (Vol. 25). Buenos Aires: Imprenta de Pablo E. Coni.

Teruel, A. (2016). El Marquesado del Valle de Tojo. Patrimonio y Mayorazgo en Bolivia y Argentina. Revista de Indias, $77(267), 379-418$.

Troisi Melean, J. (2012). La Compañía de Jesús en las estrategias familiares coloniales: Catamarca, siglos XVII-XVIII. Anuario del Instituto de Historia Argentina, 12, 123-145.

Vilgré La Madrid, A. (1977). El mayorazgo de Guazán. En Bicentenario del Virreinato del Río de la Plata (Tomo II, pp. 304-305). Buenos Aires: Academia Nacional de la Historia.

\section{Notas}

1 Proyecto Agencia Nacional de Promoción Científica y Tecnológica-Argentina (PICT 2016-0503) “Tierras comunales, mayorazgos y campos comuneros: abordajes históricos, jurídicos y antropológicos en torno a la indivisión de la propiedad en Catamarca, La Rioja, Tucumán, Córdoba y Santiago del Estero, siglo XVIII hasta la actualidad”.

2 AHC, Sucesorios, Caja 24, Expte. 1007, Año 1809.

3 “Relación geográfica de la jurisdicción de Catamarca por el general don Luis José Díaz, 1755”. En Larrouy y Soria, (1921, pp. 226-228). 
4 En su testamento declaró expresamente no tenerlos y tampoco hubo reclamos posteriores.

5 Por esta razón tenía casas de vivienda en ambas ciudades, avecindándose finalmente en la de Catamarca.

6 Santa Rita de Huasán era conocida como "estancia" cuando don Luis la adquirió del presbítero Francisco de Cubas (Bustos Argañaráz, 1979, p. 31). Sin embargo, al convertirse en la residencia de Díaz, se la llamó "haciendas de casas" o bien la "Hacienda de Santa Rita de Guasán”; así figura en su testamento (AHC, Sucesorios, Caja 24, exp. 1007, f. 40 y 40v). En este trabajo utilizaremos los términos estancia o hacienda tal como figuran en cada uno de los documentos que citamos.

7 Sobre las tierras de este poblado indígena -también encomienda- y acerca de la conformación de la estancia contamos con el completo trabajo de Bustos Argañaráz (1987), que incluye su devenir en el contexto del mayorazgo y los conflictos por la sucesión.

8 Bustos Argañaráz sostiene, siguiendo a Ramón Rosa Olmos, que las estancias cedidas a los jesuitas para fundar un colegio en Catamarca eran las de Amamato y Santa Rosa, cuyo valor habría ascendido a 50.000 pesos (1979, p. 31). Troisi Melean reproduce esta información y analiza las relaciones entre Díaz y la Compañía, señalando que se trató de una alianza basada en intereses económicos y político judiciales (2012).

9 Incluyendo una chacra que les cedió a los padres Mercedarios para que se establecieran en Catamarca, con cargo "de decir todos los años doce misas rezadas y una cantada por dichas benditas almas [del purgatorio]".

10 Es interesante notar que Díaz hizo una "promesa y contrato" con las almas del purgatorio, comprometiéndose entonces (1726) a dar por cada $\$ 100$ que obtuviere (dice "por el aumento en contratos, producciones de hacienda, cría de ganados y toda producción”), \$11 para las almas del purgatorio, mandas que había cumplido con puntualidad (y que recomendaba a sus herederos siguieran realizando). Esto muestra que Díaz tenía muy claro su plan estratégico para hacer fortuna, aunque no sabemos de manera certera a qué socios, mecanismos o recursos acudió para comenzar a efectivizarlo en el Tucumán.

11 Archivo General de Indias, Visita al Mineral de Aconquija, Año 1762, f. 50 y ss. Transcripción depositada en la Biblioteca "Ing. Carlos Stubbe" del Instituto de Geología y Minería de la Universidad Nacional de Jujuy (Argentina).

12 La investigación de Gómez Serrano sobre la hacienda - mayorazgo de Ciénaga de Mata en la Nueva Galicia muestra cómo en la larga duración el destino de estos complejos emprendimientos dependía mucho de la capacidad de gestión de sus titulares y de cómo pudieran adaptarse a los contextos políticos; la familia Rincón Gallardo debió apurar la fragmentación del latifundio (cuando el mayorazgo en sí ya no existía) antes de la reforma agraria previendo que las políticas por venir podían perjudicar la integridad de tan extenso patrimonio y de sus réditos (Gómez Serrano, 2017, p. 142).

13 El fundador expresa con claridad la organización jerárquica de la producción en su testamento ya que enumeró en primer lugar las dos haciendas -Santa Rita y Santa Bárbara- y luego las estancias y potreros "de donde se proveen dichas haciendas" (AHC, Sucesorio, Caja 24; Expte. 1007, Año 1809, Particiones de bienes de Salvador Díaz de la Peña, Testamento de José Luis Díaz).

14 La cláusula testamentaria erige a don Salvador como heredero universal de "todos mis bienes así los de la institución del mayorazgo como todos los demás que se reconozcan ser míos con tal que cumpla y guarde lo que llevo dispuesto y ordenado en este mi testamento" (AHC, Sucesorio, Caja 24; Expte. 1007).

15 En su testamento declaró no haber recibido ninguna legítima por parte de padre o madre; finalmente quedó como único heredero de "casas y todo homenaje" que tenían en su ciudad natal, pero le indicó a su madre que donara esos pocos bienes al pariente cercano más necesitado (AHC, Sucesorio, Caja 24; Expte. 1007). En esto procedió exactamente igual que su tío don Luis José Díaz.

16 Una producción semejante en frutales aunque en menor escala fue inventariada en la hacienda del Molino, externa al mayorazgo según la carta de institución pero desdibujada entre los bienes comunes al vínculo en 1809 . No ha sido posible reconocer aún si fue incorporada formalmente o se trata de una estrategia para evitar su división.

17 Es notable que tampoco incluyera entre sus herederos a su hijo don Pedro Pascual Díaz, quien en efecto recibió su herencia por ser hijo legítimo. Estos “olvidos” se enmarcan en un particular racconto de su rol como progenitor; declaró que en el Reino de Chile habían nacido don Marcelo Antonio y don Luis, que falleció siendo niño, y luego, con su misma esposa -doña Francisca Xaviera Ramírez- "procreamos varios hijos que por haber muerto pequeños no tengo presentes cuántos sean ni sus nombres a excepción de la finada doña Agustina y sólo se hallan vivos al presente don Marcelo Antonio Díaz, don Manuel Díaz y Doña Juana Díaz”. Por las fechas que apunta el trabajo de Acuña (2016), es probable que doña Agustina muriera a causa del parto; así como su hijo don José Molina fue parte litigante en las partijas de don Salvador, sus descendientes lo serán del propio vínculo.

18 Autor Anónimo "Lo que es la administración de justicia en Catamarca. Por un amigo del Sr. D. Miguel Díaz de la Peña". Salta, julio de 1854, Imprenta de Tucumán. Depositado en Museo y Biblioteca Mitre (Bs. As.).

19 AHC, Causas Civiles (CC), Caja 31, Expte. 1393, Año 1851, Díaz Rosario contra Cruz Díaz pide rendición de cuentas entrega administración Huasán, f. 2. 
20 "Basta por ahora: en adelante tendrás mis cartas aún mis confianzas si te portas con decencia y delicadeza. Procura que doña Cruz haga lo mismo”. Extracto de Carta escrita por don Miguel a doña María del Rosario incluida en el expediente antes citado, f. 1.

21 AHC, CC, Caja 30, Expte. 1329, Año 1846, Juicio seguido por Josefa Figueroa contra Miguel Díaz de la Peña por cobro de pesos y AHC, CC, Caja 30, Expte.1337, Año 1847, Pio Isaac Acuña por doña Josefa Figueroa pide que el hijo de su representada, Miguel Díaz, le suministre alimentos.

22 Cabe recordar que, por esos años, Malbrán habría estado a la cabeza del ingenio denominado Mercedes en la quebrada de Choya y constituiría uno de los apellidos destacados de la minería catamarqueña (Catalano, 2004; Rojas, 2013).

23 AHC, CC, Caja 33, Expte. 1477, Año 1855, Cabero María. Sobre autorización para vender bienes de Huasán, Andalgalá, f. 1 vta. Señala Mariluz Urquijo (1970, p. 72) que es el último pedido de esta clase presentado en el país y que se argumentaba por la utilidad del mayorazgo. El titular no podía accionar libremente sobre los bienes del mayorazgo, siendo preciso solicitar licencia durante la vigencia del orden colonial, a las Reales Audiencias, de acuerdo con el régimen indiano.

24 República Argentina. Informes de los Consejeros Legales del Poder Ejecutivo (de 1825 a 1866 inclusive). Tomo III, Publicación oficial. Buenos Aires, Taller Tipográfico de la Penitenciaría, 1891.

25 Archivo Histórico de Tucumán (AHT), Sección Administrativa, vol. 71, fs. 604-607. Documento transcripto por Levaggi (2012).

26 Compilación ordenada de leyes, decretos y mensajes del periodo constitucional de la provincia de Tucumán, que comienza en el año 1852, I, Tucumán, edición oficial, 1915, pp. 372-373.

27 Manuel Navarro fue gobernador de la provincia de Catamarca entre 1834 y 1835 y luego entre 1846 y 1847 y entre 1848 y 1852. Samuel Molina fue gobernador entre 1858 y 1862 (Larrouy, 1921).

28 "Que la legislatura de la Provincia de Catamarca por resoluciones de cuatro de Setiembre y veinte y seis de Noviembre de mil ochocientos cincuenta y siete desvinculó del mayorazgo de Guasan la Estancia de Singuil y autorizó á su actual poseedor á venderla, y con su importe reparar y mejorar la parte restante del mayorazgo, (fojas cuatro y cinco del primer cuerpo de autos)". En Tarnassi y Domínguez (1884, p. 223).

29 AHC, CC, Caja 34, Expte. 1551, Año 1857, Priestley Enrique contra Quiroga Luis. Rescisión de un contrato.

30 AHC, CC, Caja 35, Expte. 1575, Año 1858, Molina Hilario con Elisa Díaz, Sobre mejor derecho al mayorazgo de Huasán. En este expediente asimismo se puede observar que don Hilario también hubo de disputar el mayorazgo con otras dos oponentes: doña Débora Figueroa (sobrina de don Miguel por parte de su hermana Rosario) y doña Petrona Boter (hija de doña Juana Díaz de la Peña y nieta de don Salvador Díaz de la Peña), llegando en ambos casos a un acuerdo con las partes en litigio. El conflicto entre todos estos actores sociales, que no podemos detallar aquí, puede seguirse además en: AHC, CC, Expte. 1597, Año 1858, Boter Petrona, Molina Hilario, Figueroa Débora y Díaz de la Peña Elisa. Sobre derecho al mayorazgo de Huasán.

31 AHC, CC, Caja 44, Expte. 2031, Año 1863, Documento citado por Bustos Argañaráz (1979).

32 AHC, CC, Caja 35, Expte. 1597, Año 1858, Boter Petrona, Molina Hilario, Figueroa Débora y Díaz de la Peña Elisa. Sobre derecho al mayorazgo de Huasán, f. 9.

33 AHC, CC, Caja 36, Expte. 1641, Año 1858, Hilario Molina contra Díaz de Priestley Elisa. Sobre mejor derecho al mayorazgo de Huasán, f. 31.

34 AHC, CC, Caja 40, Expte. 7054, Año 1860, Molina Hilario contra Díaz Elisa. Sobre el mayorazgo de Huasán, f. 1vta.

35 El 25 de enero de 1859, don Hilario y don Vicente firmaron un contrato en el que estipulaban los detalles del trabajo conjunto. Resulta interesante que mientras Hilario se "obliga[ba] a comprometer personalmente el trabajo...Lezana se obliga[ba], como abogado, a defender las cuestiones actuales que [sostenía] el señor Molina”. El acuerdo no duraría mucho tiempo, un año después de celebrado el contrato las partes entraban en conflicto. AHC, CC, Caja 40, Expte. 1828, Año 1860, Lezana Vicente contra Molina Hilario. Por derechos en el mayorazgo de Huasán, f. 3.

36 En 1860, el apoderado de la menor Débora Figuera reclamaba ante la justicia que don Hilario pagara el arriendo correspondiente ( $\$ 2300$ anuales) y que además se le pasaran alimentos “como presunta poseedora hasta la terminación del juicio de concurso". Por supuesto, a esto se oponía además doña Elisa quien afirmaba que de pagarse esos arriendos debían ir a parar a sus manos y que de efectuarse el pago ella haría "la gracia que me sea posible en obsequio de la señorita Débora”. AHC, CC, Caja 40, Expte. 1804, Año 1860, Débora Figueroa, Petición de alimentos de los productos de los arriendos de la Hacienda de Huasán.

37 AHC, CC, Caja 40, Expte. 1804, Año 1860, Débora Figueroa, Petición de alimentos de los productos de los arriendos de la Hacienda de Huasán.

38 AHC, CC, Caja 44, Expte. 2031, Año 1863. Documento citado por Bustos Argañaráz (1979).

39 Entre otras cosas relativas a la minería. Hay que recordar que para esta época la extracción de la sierra de Capillitas ya se ha reavivado y existen varios ingenios mineros que procesan mineral en la zona. Samuel Lafone Quevedo, dueño de una de las empresas mineras más importantes (La Restauradora), tendrá varios pleitos judiciales con don Hilario. 
Roxana Boixadós, et al. Una hacienda en JaQue: el Mayorazgo de Huasán y los desafíos de las trans...

40 Vilgré La Madrid consigna que en 1888 los hermanos Molina y Wellington Mercado vendieron las tres cuartas partes de Antofagasta, la antigua merced, generándose un nuevo pleito que se ventiló en los estrados de la Corte Suprema (1977, p. 311). Sobre la "desaparición" de Antofagasta habrá que averiguar si no pesaron al respecto los cambios jurisdiccionales sobre dicha región. "El área perteneció desde 1825 a 1883 a Bolivia, desde 1884 a 1899 a Chile y a partir de entonces a Argentina a la cual se integró como el Territorio de los Andes (1900-1943)" (Quesada y Lema, 2011). Sobre el "período boliviano" hay que considerar que aparentemente don Miguel aprobó la incorporación de Antofagasta. "El dueño de Antofagasta, que es el ex-gobernador de Catamarca, D. Miguel Díaz de la Peña, se encontraba exilado en Bolivia y él no sólo aprueba esta incorporación sino que escribe incitando a los catamarqueños que se incorporen a Bolivia, donde hay paz y orden para trabajar, ¡Consecuencias de la guerra civil!”(Sánchez Oviedo, 1942, p. 24).

41 El tema requiere una investigación más profunda y la consulta de otras fuentes ya que hay propiedades cuya localización e incorporación al patrimonio familiar son confusas. Lo más probable es que se tratara de bienes "satélite", destinados a financiar o sostener el capital del mayorazgo.

42 AHT, "Juan Heller. Cartas del Libro Copiador desde 18/10/1862 hasta 22/05/1870", fs. 336-341. Sobre la relación entre las propiedades del mayorazgo y la empresa minera La Restauradora, véase Rodríguez (2017).

43 Pueden consultarse estas propiedades en el testamento de Samuel Lafone Quevedo. AHC, Sucesorios, Caja 341, Año 1924, "Lafone Quevedo, Samuel Alejandro (Testamento), Capital".

44 AHT, "Juan Heller. Cartas del Libro Copiador desde 18/10/1862 hasta 22/05/1870”, fs. 348 a 351 . El resaltado es nuestro.

45 AHT, “Juan Heller. Cartas del Libro Copiador desde 18/10/1862 hasta 22/05/1870”, fs. 100 a 103.

46 La legislación indiana recuperó la tradición medieval que también contemplaba la enajenación en ciertas circunstancias; cfr. Quintanilla Raso, 2004.

\section{BY-NC-SA}

